Check for updates

Cite this: RSC Adv., 2019, 9, 24212

Received 25th June 2019 Accepted 30th July 2019

DOI: $10.1039 / c 9 r a 04768 a$

rsc.li/rsc-advances

\section{Organocatalytic enantioselective conjugate addition of 2-naphthols to ortho-hydroxyphenyl substituted para-quinone methides: access to unsymmetrical triarylmethanes $\uparrow$}

\author{
Yuyu Cheng, ${ }^{a}$ Zhiqiang Fang, ${ }^{a}$ Yanwen Jia, ${ }^{a}$ Zhongyue Lu, ${ }^{a}$ Wenjun Li (D) *b \\ and Pengfei Li iD *a
}

\begin{abstract}
The enantioselective conjugate addition of 2-naphthols to ortho-hydroxyphenyl substituted para-quinone methides has been achieved with the aid of a chiral phosphoric acid. Importantly, the reaction took place with excellent chemo- and regioselectivities. In addition, the protocol features a low catalyst loading, mild reaction conditions, and enables the formation of unsymmetrical triarylmethanes in good to high yields with generally high enantioselectivities.
\end{abstract}

Unsymmetrical triarylmethanes, especially enantiomerically enriched triarylmethanes have been regarded as unique structural frameworks due to their remarkable significance in materials science, natural products, and medicinal chemistry. ${ }^{1}$ Accordingly, much effort has been devoted to developing catalytic synthetic methodologies for accessing these motifs, ${ }^{2}$ especially in a enantioselective fashion. ${ }^{3}$ However, besides limited examples of transition metal-mediated construction of chiral triarylmethanes, ${ }^{4}$ there are only a few organocatalytic enantioselective synthetic strategies, ${ }^{5-9}$ of which most processes focused on transformations of indolylmethanols (Scheme 1A), ${ }^{10}$ in situ generated ortho-quinone methides (o-QMs, Scheme 1B),$^{11}$ and para-quinone methides ( $p$-QMs, Scheme 1C)..$^{12}$ On the other hand, triarylmethanes containing the 2-naphthol moiety is a family of biologically active compounds, ${ }^{13}$ but reports on catalytic enantioselective construction of triarylmethanes bearing the 2-naphthol motif are very limited. ${ }^{14}$ In 2015, Schneider et al. realized the enantioselective construction of chiral triarylmethanes via a chiral phosphoric acid (CPA) catalyzed 1,4-addition of 2-naphthol to $o$ QMs generated from ortho-hydroxy benzhydrols (Scheme 2A). ${ }^{15}$ Similarly, in the presence of squaramide combined with excess base as acid scavenger, Xu et al. established an enantioselective 1,4-addition of 2-naphthols to in situ

${ }^{a}$ Department of Chemistry and Shenzhen Key Laboratory of Marine Archaea Geo-Omics, Southern University of Science and Technology, Shenzhen, Guangdong, 518055, China.E-mail: lipf@sustech.edu.cn; flyli1980@gmail.com

${ }^{b}$ Department of Medicinal Chemistry, School of Pharmacy, Qingdao University, Qingdao, Shandong, 266021, China. E-mail: liwj@qdu.edu.cn

$\dagger$ Electronic supplementary information (ESI) available. CCDC 1908826. For ESI and crystallographic data in CIF or other electronic format see DOI: $10.1039 / \mathrm{c} 9 \mathrm{ra} 04768 \mathrm{a}$ generated $o$-QMs from 2-[phenyl(tosyl)methyl]phenols (Scheme 2B). ${ }^{16}$ Independently, Sun et al. developed a CPA catalyzed 1,6-addition between 2-naphthols and $p$-QMs in situ generated from para-hydroxy benzhydrols to construct the optically active triarylmethanes bearing 2-naphthol motif (Scheme 2C). ${ }^{17}$ In spite of these elegant approaches, the organocatalytic enantioselective construction of chiral

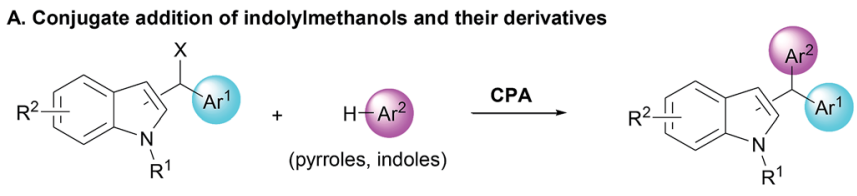

$\mathrm{X}=\mathrm{OH}$, OTMS, NHTS

B. Conjugate addition of ortho-quinone methides and their derivatives

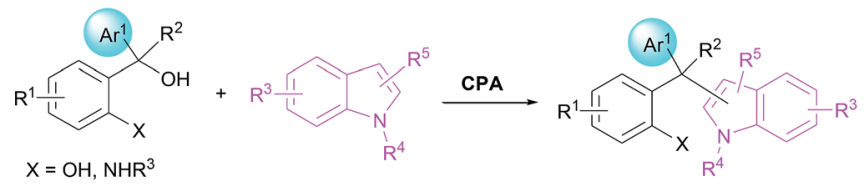

C. Conjugate addition of para-quinone methides

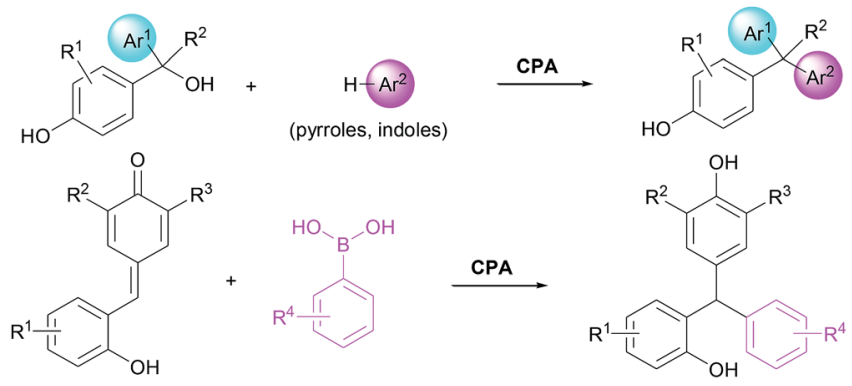

Scheme 1 Organocatalytic enantioselective construction of chiral triarylmethanes. 
A. In 2015 , Schnerder et al. via ortho-quinone methides

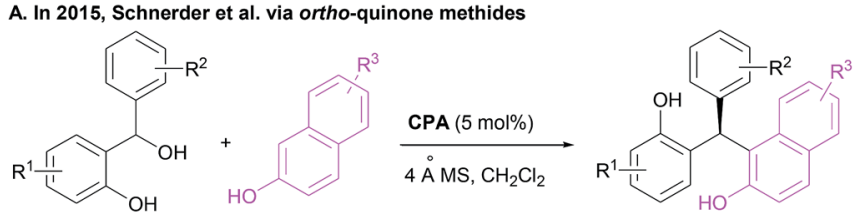

17 examples, $90-95 \%$ yields, $74-98 \%$ ee

B. In 2017, Xu et al. via ortho-quinone methides

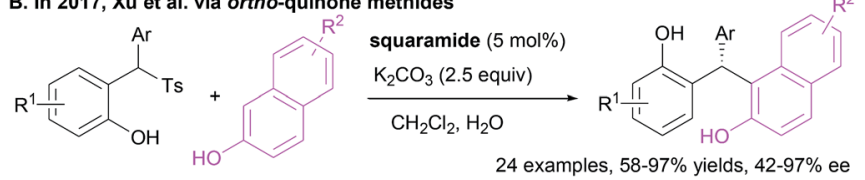

24 examples, $58-97 \%$ yields, $42-97 \%$ ee

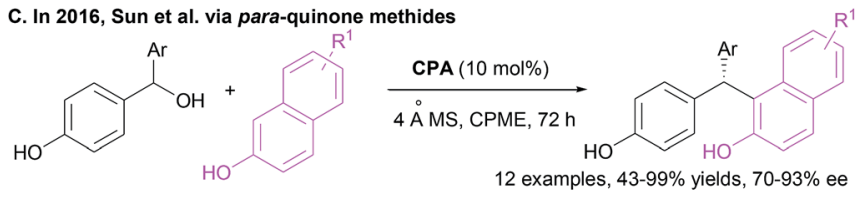

D. This work, via para-quinone methides

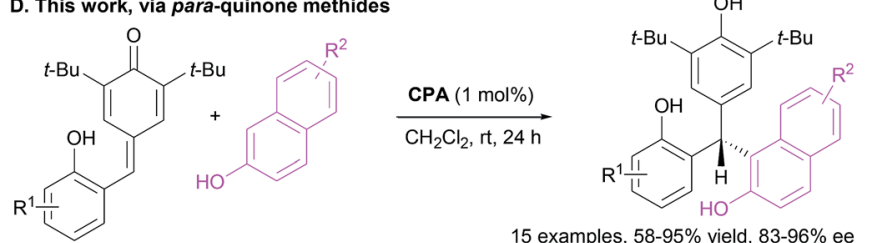

15 examples, $58-95 \%$ yield, $83-96 \%$ ee Excellent chemoselectivity, excellent regioselectivity, low catalyst loading, mild conditions

Scheme 2 Limited examples and our work for chiral triarylmethanes bearing naphthol motif.

triarylmethanes still represents a challenging task. Therefore, a direct and facile synthetic strategy for this important structural motif would be highly valuable. On the basis of asymmetric additions to ortho-hydroxyphenyl substituted para-quinone methides ${ }^{\mathbf{1 8 , 1 9}}$ and as a continuation of our efforts in asymmetric reactions of $p$-QMs,${ }^{20}$ we report herein a direct and efficient CPA-mediated asymmetric conjugate addition of 2-naphthols to $p$-QMs (Scheme 2D).

Initial investigations were carried out using a series of CPAs for the model reaction of 4-(2-hydroxybenzylidene)2,6-di-tert-butylcyclohexa-2,5-dienone 1a with 2-naphthol 2a in dichloromethane at room temperature for $24 \mathrm{~h}$. As shown in Table 1, with a catalyst loading of $10 \mathrm{~mol} \%$, CPA-1 mediated reaction proceeded smoothly to afford the triarylmethane 3 aa in $81 \%$ yield with $5 \%$ ee (entry 1 ). An essential enhancement was achieved when the reaction was catalyzed by CPA-3, furnishing 3aa in $90 \%$ yield with $91 \%$ ee (entry 3). To our delight, further modification of catalyst structure led to the formation of $3 \mathbf{a a}$ in $95 \%$ yield with $94 \%$ ee (entry 5). With CPA-5 as the suitable catalyst, reaction media was screened (entries 7-11). Solvent was found to have a great influence on the reaction efficiency and stereoselectivity, and dichloromethane was identified as the best reaction media. Notably, decreasing the catalyst loading from $10 \mathrm{~mol} \%$ to $1 \mathrm{~mol} \%$, the desired triarylmethane 3aa was still obtained in $95 \%$ yield with $94 \%$ ee when the reaction was carried out in $\mathrm{CH}_{2} \mathrm{Cl}_{2}$ of $1.0 \mathrm{~mL}$ at room temperature for $24 \mathrm{~h}$ (entry 12). Shorting reaction time from $24 \mathrm{~h}$ to $12 \mathrm{~h}$, the yield of triarylmethane $\mathbf{3 a a}$ decreased from $95 \%$ to $83 \%$ without compromising the enantioselectivity (entry 13).

Having optimized the catalyst structure and reaction conditions, we then explored the substrate scope of this organocatalytic enantioselective transformation. Firstly, the generality of 2-naphthols component was evaluated (Table 2). Pleasingly, a wide range of 2-naphthols $2 \mathbf{a}-\mathbf{h}$ reacted smoothly with $p$-QM $1 \mathrm{a}$ to afford the corresponding enantioenriched triarylmethanes 3aa-ah in high yields (7095\%) with excellent enantioselectivities (93-96\%). Various different substituents, including electron-withdrawing $(\mathrm{Br}$, $\mathrm{CN}, \mathrm{CO}_{2} \mathrm{Me}, \mathrm{CO}_{2} \mathrm{Et}$ ) and electron-donating groups $(\mathrm{MeO}$, EtO) at different positions of the aromatic ring of the 2naphthols component were tolerated with only slight effects on the reaction efficiency and asymmetric induction. No significant electronic effects were observed for the substituents on the aromatic moiety. Confirmed by the impressive results, the organocatalytic enantioselective conjugate addition of $p$-QMs has been successfully extended to a variety of 2-naphthols and provided an efficient and facile access to optically active triarylmethanes.

\section{Table 1 Optimization of the reaction conditions ${ }^{a}$}

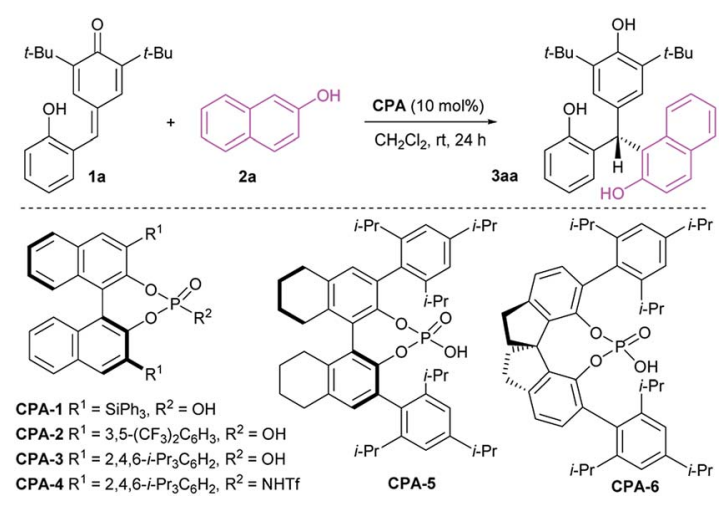

\begin{tabular}{|c|c|c|c|c|}
\hline Entry & Catalyst & Solvent & Yield $^{b}(\%)$ & $\mathrm{ee}^{c}(\%)$ \\
\hline 1 & CPA-1 & $\mathrm{CH}_{2} \mathrm{Cl}_{2}$ & 3aa, 81 & 5 \\
\hline 2 & CPA-2 & $\mathrm{CH}_{2} \mathrm{Cl}_{2}$ & 3aa, 77 & 28 \\
\hline 3 & CPA-3 & $\mathrm{CH}_{2} \mathrm{Cl}_{2}$ & 3aa, 90 & 91 \\
\hline 4 & CPA-4 & $\mathrm{CH}_{2} \mathrm{Cl}_{2}$ & 3aa, 56 & 3 \\
\hline 5 & CPA-5 & $\mathrm{CH}_{2} \mathrm{Cl}_{2}$ & 3aa, 95 & 94 \\
\hline 6 & CPA-6 & $\mathrm{CH}_{2} \mathrm{Cl}_{2}$ & 3аa, 91 & 35 \\
\hline 7 & CPA-5 & $\mathrm{CHCl}_{3}$ & 3aa, 90 & 88 \\
\hline 8 & CPA-5 & EtOAc & 3aa, 70 & 69 \\
\hline 9 & CPA-5 & Toluene & 3aa, 84 & 88 \\
\hline 10 & CPA-5 & THF & 3aa, 59 & 10 \\
\hline 11 & CPA-5 & $\mathrm{MeCN}$ & 3aa, 83 & 94 \\
\hline $12^{d}$ & CPA-5 & $\mathrm{CH}_{2} \mathrm{Cl}_{2}$ & 3aa, 95 & 94 \\
\hline $13^{e}$ & CPA-5 & $\mathrm{CH}_{2} \mathrm{Cl}_{2}$ & 3aa, 83 & 93 \\
\hline
\end{tabular}

${ }^{a}$ Unless noted, 1a $(0.20 \mathrm{mmol}), 2 \mathrm{a}(0.24 \mathrm{mmol})$, catalyst $(10 \mathrm{~mol} \%)$ in the solvent $(2.0 \mathrm{~mL})$ at room temperature for $24 \mathrm{~h} .{ }^{b}$ Isolated yield. ${ }^{c}$ Determined by HPLC analysis using a chiral stationary phase. ${ }^{d} \mathbf{C P A}-$ $5(1 \mathrm{~mol} \%), \mathrm{CH}_{2} \mathrm{Cl}_{2}(1.0 \mathrm{~mL}) .{ }^{e}$ CPA-5 $(1 \mathrm{~mol} \%), \mathrm{CH}_{2} \mathrm{Cl}_{2}(1.0 \mathrm{~mL}), 12 \mathrm{~h}$. 
Table 2 Scope of 2-naphthols ${ }^{a}$
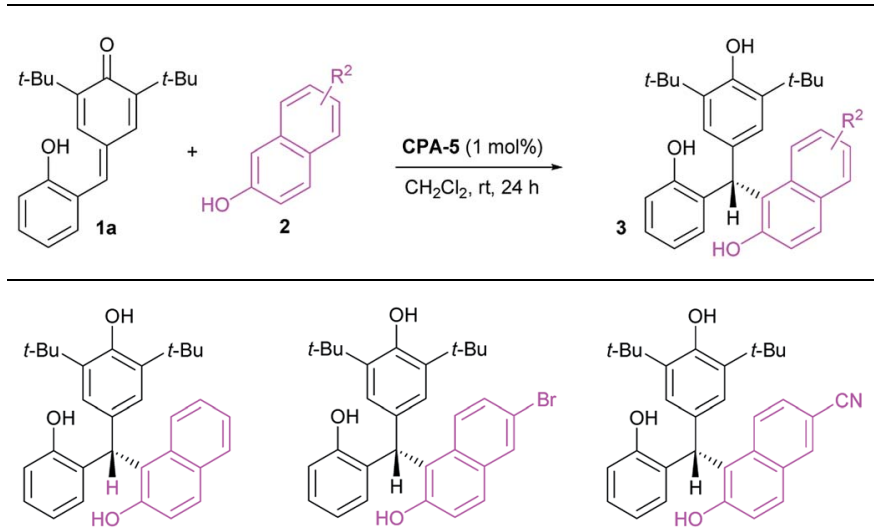

3aa $95 \%$ yield, $94 \%$ ee

3ab $70 \%$ yield, $95 \%$ ee

3ac $80 \%$ yield, $96 \%$ ee

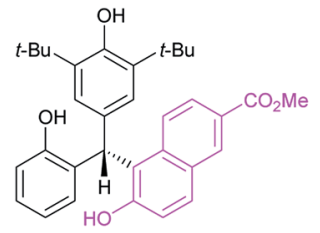

3ad $85 \%$ yield, $96 \%$ ee

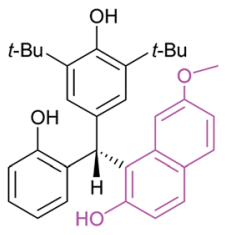

3ag $85 \%$ yield, $93 \%$ ee

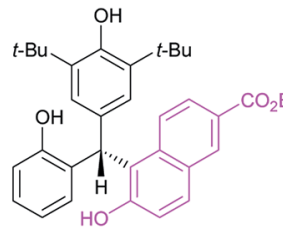

3ae $84 \%$ yield, $93 \%$ ee

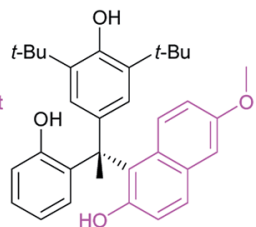

3af $92 \%$ yield, $95 \%$ ee

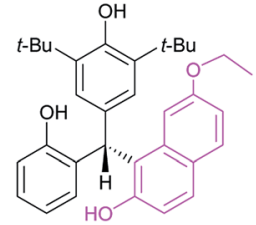

3ah $89 \%$ yield, $93 \%$ ee

${ }^{a}$ Unless noted, 1a $(0.20 \mathrm{mmol}), 2(0.24 \mathrm{mmol})$, CPA-5 $(1 \mathrm{~mol} \%)$ in $\mathrm{CH}_{2} \mathrm{Cl}_{2}(1.0 \mathrm{~mL})$ at room temperature for $24 \mathrm{~h}$. Products 3aa-ah were obtained in isolated yield and ee values were determined by chiral HPLC analysis.

With these encouraging data in hand, we then investigated the substrate scope of $p$-QMs 1 in the CPA-5 catalyzed conjugate addition of 2-naphthol 2a (Table 3). It was found that this strategy was applicable to various $p$-QMs $\mathbf{1 b}-\mathbf{h}$ bearing different types of substituents to furnish the corresponding optically active triarylmethanes $3 \mathbf{b a}-\mathbf{h a}$ in generally high yields with enantioselectivities. Both electron-withdrawing $(\mathrm{F}, \mathrm{Cl}, \mathrm{Br})$ and electron-donating groups $(\mathrm{Me}, \mathrm{MeO})$ could be introduced into different positions of the aromatic ring of $p$-QMs with a little effect on the reaction efficiency and stereoselectivity. The absolute configuration of 3 ha was unambiguously confirmed by X-ray crystallography. ${ }^{21}$ In all, a broad scope of $p$-QMs has been successfully involved in the organocatalytic conjugate addition of 2-naphthols for the chemo-, regio- and enantioselective construction of chiral triarylmethanes.

To demonstrate the robustness and utility of this synthetic strategy, the scale up of the reaction were carried out (Scheme 3A). The CPA-5 mediated conjugate reaction of $p$-QM 1a at $1.0 \mathrm{mmol}$ proceeded well under the standard conditions to generate 3 aa in $82 \%$ yield with $93 \%$ ee. When
Table 3 Scope of para-quinone methides. ${ }^{a}$
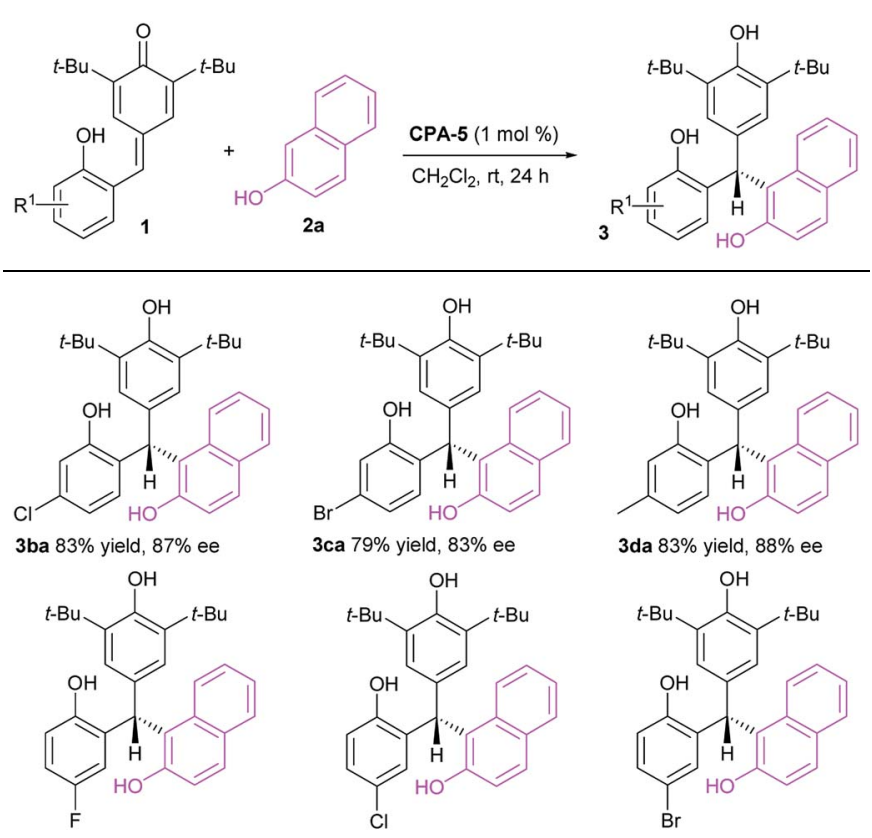

3ca $79 \%$ yield, $83 \%$ ee

3da $83 \%$ yield, $88 \%$ ee

3ea $95 \%$ yield, $91 \%$ ee

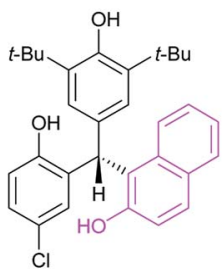

3fa $90 \%$ yield, $93 \%$ ee

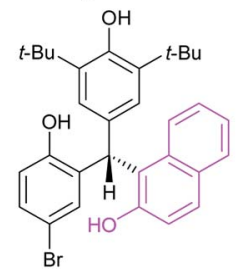

3 ga $58 \%$ yield, $92 \%$ ee

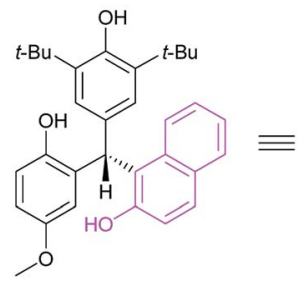

3ha $91 \%$ yield, $95 \%$ ee

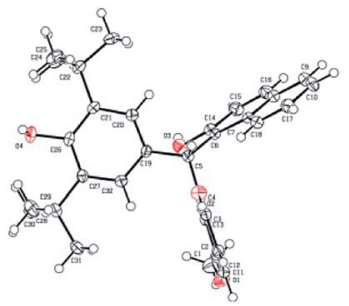

${ }^{a}$ Unless noted, $1(0.20 \mathrm{mmol}), 2 \mathrm{a}(0.24 \mathrm{mmol}), \mathbf{C P A}-5(1 \mathrm{~mol} \%)$ in $\mathrm{CH}_{2} \mathrm{Cl}_{2}(1.0 \mathrm{~mL})$ at room temperature for $24 \mathrm{~h}$. Products 3 ba-ha were obtained in isolated yield and ee values were determined by chiral HPLC analysis.

the reaction was scaled up to $4.5 \mathrm{mmol}$, the product $3 \mathrm{aa}$ was obtained in $84 \%$ yield with $95 \%$ ee, which indicated this protocol has the potential for a large-scale production. The reaction of 1-naphthol furnished racemic products in $76 \%$ yield under standard conditions (Scheme 3B). The transformation of 3aa was also investigated. Treated with $\mathrm{PhI}(\mathrm{OAc})_{2}$, product 4 aa was isolated in $31 \%$ yield with $96 \%$ ee (Scheme 3C). Then employing 3aa as ligand in catalytic asymmetric aldol reaction was surveyed. The initial result indicated that the $\mathrm{Ti}(\mathrm{Oi}-\mathrm{Pr})_{4} / 3$ aa system mediated the asymmetric aldol reaction of $\mathrm{ZnEt}_{2}$ to 2-naphthaldehyde effectively to generate adduct in 59\% yield, although the enantioselectivity was low (Scheme 3D).

To light some insight into the reaction mechanism, control experiments were carried out (Scheme $4 \mathrm{~A})$. When the hydroxyl group of $p$-QM 1a was shielded by $t$-butyldimethylsilyl (TBS) group ( $p$-QM 5a), the reaction was found to proceed quite slowly and the corresponding product $6 \mathbf{6 a}$ was 
A. Scale up of the reaction

$$
1 \mathrm{a}+2 \mathrm{a} \quad \frac{\mathrm{CPA}-5(1 \mathrm{~mol} \%)}{\mathrm{rt}, 24 \mathrm{~h}} \text { 3aa }
$$

1) $1 \mathrm{a}(1.0 \mathrm{mmol}), 2 \mathrm{a}(1.2 \mathrm{mmol}), \mathrm{CH}_{2} \mathrm{Cl}_{2}$ (10 mL), 3aa: $381.1 \mathrm{mg}, 82 \%$ yield, $93 \%$ ee 2) 1a (4.5 mmol), 2a (5.4 mmol), $\mathrm{CH}_{2} \mathrm{Cl}_{2}$ ( $45 \mathrm{~mL}$ ), 3aa: $1811.2 \mathrm{mg}, 84 \%$ yield, $95 \%$ ee

B. Limitation of the substrate scope<smiles>CC(C)(C)C1=CC(=Cc2ccccc2O)C=C(C(C)(C)C)C1=O</smiles>

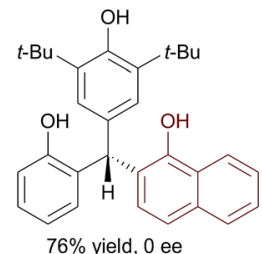

C. Transformation of 3aa

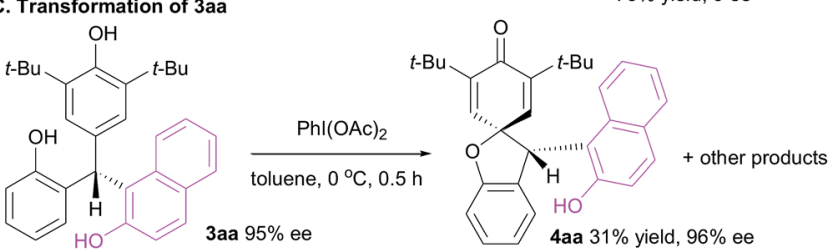

D. Application of 3 aa as ligand in asymmetric aldol reaction

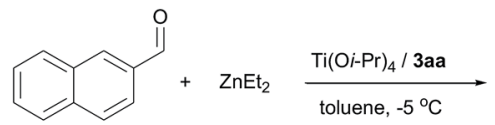

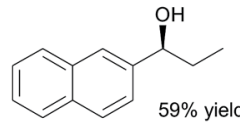

Scheme 3 Further investigations.

obtained in $11 \%$ yield after $72 \mathrm{~h}$. The yield of 6 aa could be improved to $86 \%$ when the catalyst loading was increased to $10 \mathrm{~mol} \%$, however, the enantioselectivity remained poor (16\% ee). When the hydroxyl group was removed, $p$-QM $5 \mathbf{b}$ could also reacted smoothly with 2 a to generate the adduct 6ba in $70 \%$ yield with $29 \%$ ee under the standard conditions. Consequently, it is not too hard to make the case that the free hydroxyl group of $p$-QM 1a played a key role in terms of the reaction efficiency and stereoselectivity. Based on these results and considering reported plausible transition state, ${ }^{22}$ a possible reaction mechanism was suggested. As shown in Scheme 4B, $p$-QM 1a was protonated and activated in the presence of CPA-5. Then, both $p$-QM 1a and 2-naphthol 2a were arranged by CPA-5 via hydrogen bond to generate the desired product 3aa in high yield with high enantioselectivity. Particularly, Li et al. reported that the isomerization energy of $1 \mathrm{a}$ and $\mathbf{1}^{\prime} \mathbf{a}$ was $6.7 \mathrm{kcal} \mathrm{mol}^{-1}$, indicating that the transformation of $p$-QM 1a to $o-\mathrm{QM} \mathbf{1}^{\prime} \mathbf{a}$ was not difficult. ${ }^{19 g}$ As a result, we could not exclude the possibility that 2-hydroxyphenyl $p$-QM 1 a isomerized initially to 6-(3,5-di-tert-butyl-4-hydroxybenzylidene) cyclohexa-2,4-dienone $\mathbf{1}^{\prime} \mathbf{a}$ and then the CPA-5 activated and oriented both $o-\mathrm{QM} \mathbf{1}^{\prime} \mathbf{a}$ and 2-naphthol 2a to afford the desired adduct 3aa with high efficiency and enantioselectivity (Scheme 4C).

In conclusion, we have established the enantioselective construction of optically active triarylmethanes bearing naphthol motif via a chiral phosphoric acid mediated conjugate addition of 2-naphthols to 2-hydroxyphenyl $p$ QMs. A series of enantioenriched (83-96\%) triarylmethanes were obtained in 58-95\% yields. Moreover, transformation

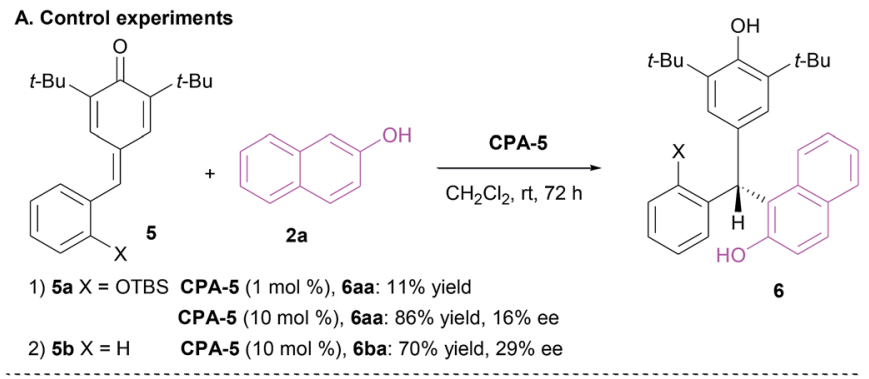

B. Proposed reaction mechanism (1)
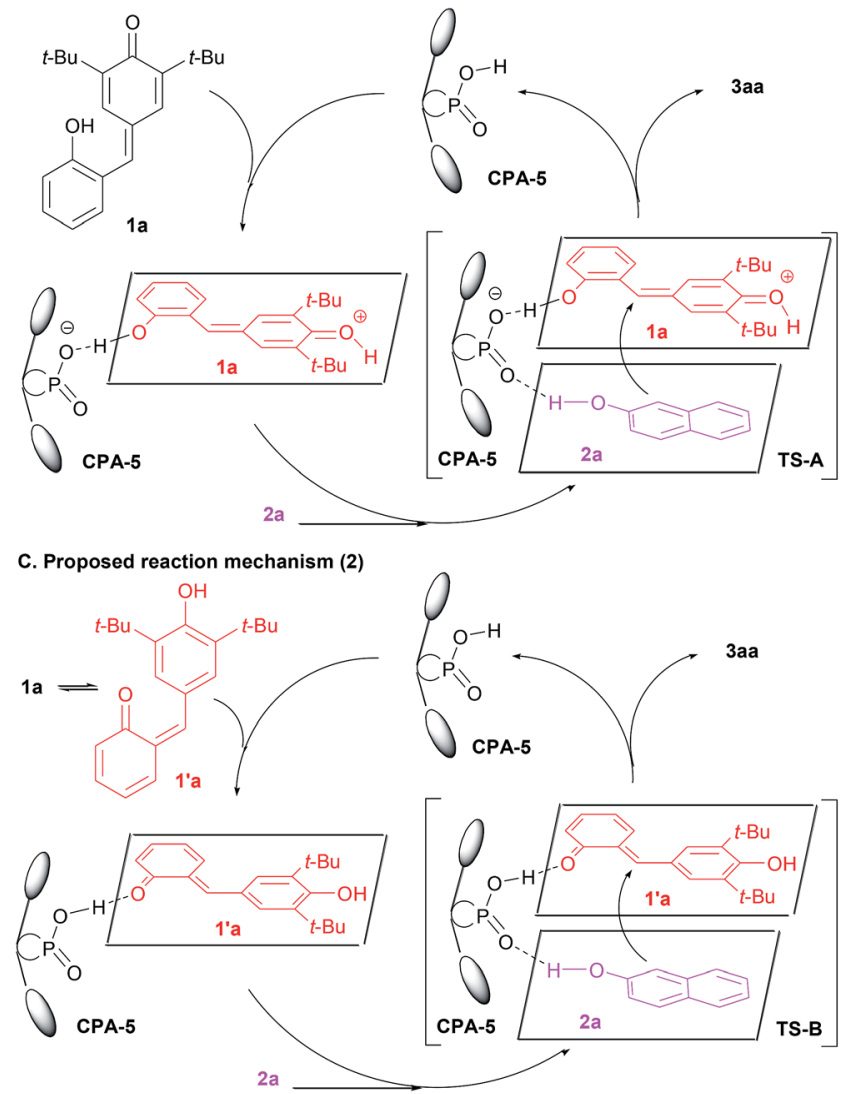

Scheme 4 Control experiments and the proposed reaction mechanism.

and application of triarylmethanes were investigated. Further modification of substrates to generate practical chiral triarylmethanes are undergoing in our lab.

\section{Conflicts of interest}

There are no conflicts to declare.

\section{Acknowledgements}

We acknowledge the financial support from National Natural Science Foundation of China (21871128), Shenzhen Innovation of Science and Technology Commission (JCYJ20170817110526264, ZDSYS201802081843490). 


\section{Notes and references}

1 For reviews, see: (a) D. F. A. Duxbury, Chem. Rev., 1993, 93, 381; (b) M. S. Shchepinov and V. A. Korshun, Chem. Soc. Rev., 2003, 32, 170; (c) V. Nair, S. Thomas, S. C. Mathew and K. G. Abhilash, Tetrahedron, 2006, 62, 6731; (d) H. N. Kim, M. H. Lee, H. J. Kim, J. S. Kim and J. Yoon, Chem. Soc. Rev., 2008, 37, 1465; (e) M. Beija, C. A. M. Afonso and J. M. G. Martinbo, Chem. Soc. Rev., 2009, 38, 2410; (f) M. Shiri, M. A. Zolfigol, H. G. Kruger and Z. Tanbakouchian, Chem. Rev., 2010, 110, 2250.

2 For reviews, see: (a) S. Mondal and G. Panda, RSC Adv., 2014, 4, 28317; (b) M. Nambo and C. M. Crudden, ACS Catal., 2015, 5,4734 .

3 For a comprehensive review, see:S. Mondal, D. Roy and G. Panda, ChemCatChem, 2018, 10, 1941.

4 (a) B.-F. Shi, N. Maugel, Y.-H. Zhang and J.-Q. Yu, Angew. Chem., Int. Ed., 2008, 47, 4882; (b) L.-L. Cao, Z.-S. Ye, G.-F. Jiang and Y.-G. Zhou, Adv. Synth. Catal., 2011, 353, 3352; (c) Y. Lou, P. Cao, T. Jia, Y. Zhang, M. Wang and J. Liao, Angew. Chem., Int. Ed., 2015, 54, 12134; (d) Y. Huang and T. Hayashi, J. Am. Chem. Soc., 2015, 137, 7556; (e) J. Zheng, L. Lin, L. Dai, X. Yuan, X. Liu and X. Feng, Chem.-Eur. J., 2016, 22, 18254; (f) J. H. Kim, S. Greßies, M. Boultadakis-Arapinis, C. Daniliuc and F. Glorius, ACS Catal., 2016, 6, 7652.

5 F.-L. Sun, M. Zeng, Q. Gu and S.-L. You, Chem.-Eur. J., 2009, 15, 8709.

6 S. Shirakawa, K. Koga, T. Tokuda, K. Yamamoto and K. Maruoka, Angew. Chem., Int. Ed., 2014, 53, 6220.

7 S. Lu, X. Song, S. B. Poh, H. Yang, M. W. Wong and Y. Zhao, Chem.-Eur. J., 2017, 23, 2275.

8 Y. Zhang, S.-X. Zhang, L.-N. Fu and Q.-X. Guo, ChemCatChem, 2017, 9, 3107.

9 A. B. Gade, P. N. Bagle, P. S. Shinde, V. Bhardwaj, S. Banerjee, A. Chande and N. T. Patil, Angew. Chem., Int. Ed., 2018, 57, 5735.

10 (a) F.-L. Sun, X.-J. Zheng, Q. Gu, Q.-L. He and S.-L. You, Eur. J. Org. Chem., 2010, 47; (b) M.-H. Zhuo, Y.-J. Jiang, Y.-S. Fan, Y. Gao, S. Liu and S. Zhang, Org. Lett., 2014, 16, 1096; (c) S. Qi, C.-Y. Liu, J.-Y. Ding and F.-S. Han, Chem. Commun., 2014, 50, 8605; (d) Y.-X. Gong, Q. Wu, H.-H. Zhang, Q.-N. Zhu and F. Shi, Org. Biomol. Chem., 2015, 13, 7993; (e) M. H. Zhuo, G.-F. Liu, S.-L. Song, D. An, J. Gao, L. Zheng and S. Zhang, Adv. Synth. Catal., 2016, 358, 808; (f) C. Yue, F. Na, X. Fang, Y. Cao and J. C. Antilla, Angew. Chem., Int. Ed., 2018, 57, 11004.

11 (a) W. Zhao, Z. Wang, B. Chu and J. Sun, Angew. Chem., Int. Ed., 2015, 54, 1910; (b) H.-H. Liao, A. Chatupheeraphat, C.-C. Hsiao, I. Atodiresei and M. Rueping, Angew. Chem., Int. Ed., 2015, 54, 15540; (c) Q. Wu, C. Ma, X.-H. Du, Y. Chen, T.-Z. Huang, X.-Q. Shi, S.-J. Tu and P.-J. Cai, Tetrahedron: Asymmetry, 2016, 27, 307.

12 (a) Z. Wang, Y. F. Wong and J. Sun, Angew. Chem., Int. Ed., 2015, 54, 13711; (b) G.-B. Huang, W.-H. Huang, J. Guo, D.-L. Xu, X.-C. Qu, P.-H. Zhai, X.-H. Zheng, J. Weng and
G. Lu, Adv. Synth. Catal., 2019, 361, 1241; (c) J.-R. Wang, X.-L. Jiang, Q.-Q. Hang, S. Zhang, G.-J. Mei and F. Shi, J. Org. Chem., 2019, 84, 7829.

13 S. K. Das, G. Panda, V. Chaturvedi, Y. S. Manju, A. K. Gaikwad and S. Sinha, Bioorg. Med. Chem. Lett., 2007, 17, 5586.

14 For catalytic non-enantioselective construction of triaylmethanes bearing 2-naphthol unit, see: (a) S. Yaragorla, P. L. Saini, P. V. Babu, A. I. Almansour and N. Arumugam, Tetrahedron Lett., 2016, 57, 2351; (b) R. Dada, G. Singh, A. Pareek, S. Kausar and S. Yaragorla, Tetrahedron Lett., 2016, 57, 3739; (c) P. Arde and R. V. Anand, RSC Adv., 2016, 6, 77111; (d) T. Zhou, S. Li, B. Huang, C. Li, Y. Zhao, J. Chen, A. Chen, Y. Xiao, L. Liu and J. Zhang, Org. Biomol. Chem., 2017, 15, 4941; (e) G.-P. Yang, D. Dilixiati, T. Yang, D. Liu, B. Yu and C.-W. Hu, Appl. Organomet. Chem., 2018, 32, e4450; (f) G. Singh, P. Goswami and R. V. Anand, Org. Biomol. Chem., 2018, 16, 384; $(g)$ G.-J. Mei, S.-L. Xu, W.-Q. Zheng, C.-Y. Bian and F. Shi, J. Org. Chem., 2018, 83, 1414.

15 S. Saha, S. K. Alamsetti and C. Schneider, Chem. Commun., 2015, 51, 1461.

16 Y. Wang, C. Zhang, H. Wang, Y. Jiang, X. Du and D. Xu, Adv. Synth. Catal., 2017, 359, 791.

17 Y. F. Wong, Z. Wang and J. Sun, Org. Biomol. Chem., 2016, 14, 5751.

18 For reviews on asymmetric reactions of $p$-QMs, see: $(a)$ A. Parra and M. Tortosa, ChemCatChem, 2015, 7, 1524; (b) W. Li, X. Xu, P. Zhang and P. Li, Chem.-Asian J., 2018, 13, 2350.

19 For examples, see: (a) K. Zhao, Y. Zhi, T. Shu, A. Valkonen, K. Rissanen and D. Enders, Angew. Chem., Int. Ed., 2016, 55, 12104; (b) S. Liu, X.-C. Lan, K. Chen, W.-J. Hao, G. Li, S.-J. Tu and B. Jiang, Org. Lett., 2017, 19, 3831; (c) Z.-P. Zhang, K.-X. Xie, C. Yang, M. Li and X. Li, J. Org. Chem., 2018, 83, 364; (d) G.-J. Mei, S.-L. Xu, W.-Q. Zheng, C.-Y. Bian and F. Shi, J. Org. Chem., 2018, 83, 1414; (e) Y. Zhi, K. Zhao, C. von Essen, K. Rissanen and D. Enders, Org. Chem. Front., 2018, 5, 1348; (f) J. Yan, M. Chen, H. H.-Y. Sung, I. D. Williams and J. Sun, Chem.-Asian J., 2018, 13, 2440; (g) Z.-P. Zhang, K.-X. Xie, C. Yang, M. Li and X. Li, J. Org. Chem., 2018, 83, 364; (h) Z.-P. Zhang, L. Chen, X. Li and J.-P. Cheng, J. Org. Chem., 2018, 83, 2714; (i) L. Liu, Z. Yuan, R. Pan, Y. Zeng, A. Lin, H. Yao and Y. Huang, Org. Chem. Front., 2018, 5, 623; (j) F. Jiang, F.-R. Yuan, L.-W. Jin, G.-J. Mei and F. Shi, ACS Catal., 2018, 8, 10234; (k) G.-H. Yang, Q. Zhao, Z.-P. Zhang, H.-L. Zheng, L. Chen and X. Li, J. Org. Chem., 2019, 84, 7883; (l) Z. Li, W. Wang, H. Jian, W. Li, B. Dai and L. He, Chin. Chem. Lett., 2019, 30, 386; (m) M. Sun, C. Ma, S.-J. Zhou, S.-F. Lou, J. Xiao, Y. Jiao and F. Shi, Angew. Chem., Int. Ed., 2019, 58, 8703.

20 (a) L. Zhang, X. Zhou, P. Li, Z. Liu, Y. Liu, Y. Sun and W. Li, $R S C A d v$., 2017, 7, 39216; (b) L. Zhang, Y. Liu, K. Liu, Z. Liu, N. He and W. Li, Org. Biomol. Chem., 2017, 15, 8743; (c) W. Li, H. Yuan, Z. Liu, Z. Zhang, Y. Cheng and P. Li, Adv. Synth. Catal., 2018, 360, 2460; (d) W. Li, X. Xu, Y. Liu, H. Gao, 
Y. Cheng and P. Li, Org. Lett., 2018, 20, 1142; (e) L. Zhang, H. Yuan, W. Lin, Y. Cheng, P. Li and W. Li, Org. Lett., 2018, 20, 4970; (f) P. Zhang, Q. Huang, Y. Cheng, R. Li, P. Li and W. Li, Org. Lett., 2019, 21, 503.

21 CCDC 1908826 (3ha).

22 For reviews, see: (a) E. P. Ávila and G. W. Amarante, ChemCatChem, 2012, 4, 1713; (b) M. Mahlau and B. List,
Angew. Chem., Int. Ed., 2013, 52, 518; for recent reports, see: (c) H. G. O. Alvim, D. L. J. Pinheiro, V. H. CarvalhoSilva, M. Fioramonte, F. C. Gozzo, W. A. da Silva, G. W. Amarante and B. A. D. Neto, J. Org. Chem., 2018, 83, 12143; (d) J. Zhang, P. Yu, S.-Y. Li, H. Sun, S.-H. Xiang, J. Wang, K. N. Houk and B. Tan, Science, 2018, 361, eaas8707. 